\title{
Perspectivas de formação: \\ diálogo entre crescimento e o cultivo de si
}

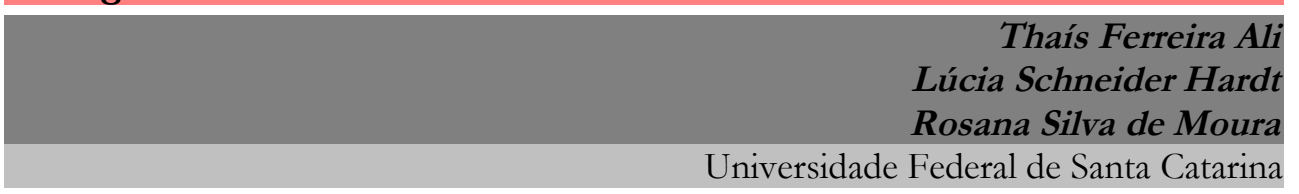

\section{Resumo}

O artigo tem como prioridade apresentar o pensamento de Dewey e sua tese de que formação é crescimento em função de uma efetiva relação com a vida. O humano é exigido pela vida a desenvolver-se, a crescer em direções muito diversas para então ocupar um espaço na sociedade. Do diálogo principal, o texto decide por introduzir outro autor, como coadjuvante para continuar a pensar o dilema da formação humana. Um texto que se faz com duas autoras, duas perspectivas contudo implicadas por um mesmo tema. Diálogos para produzir reflexão.

Palavras-chaves: formação; crescimento; vida.

\begin{abstract}
The article has as priority to present the thought of Dewey and his theory of what formation is a growth in function of an effective relation with the life. The human one is demanded by the life to develop, when are growing in very different directions so that to occupy a space in the society. Of the main dialog, the text decides since there introduces another author, like costar in order that to keep on thinking the dilemma of the human formation. A text that is done with two authors, two perspectives nevertheless implicated by the same subject. Dialogs to produce reflection.
\end{abstract}

Keywords: training; growth; life.

Filosofia e Educação [rfe] - volume 7, número 2 - Campinas, SP Junho-Setembro de 2015 - ISSN 1984-9605 - p. 143-169 


\section{Introdução}

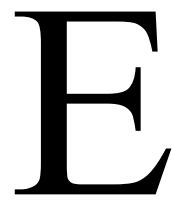

ste texto, escrito a seis mãos, repercute, em alguma medida, a convivência estabelecida no processo de orientação durante a pesquisa. ${ }^{1}$ Esta confluência de vozes procurou enfrentar o problema da formação humana mediante algumas perspectivas filosóficas ocidentais do século XIX e XX. Nosso intuito é o de constituir uma possibilidade de diálogo entre a ideia de crescimento deweyano e a ideias de cultivo de si nietzschiano. Tarefa nada fácil. Nossa argumentação em prol desta ponte, talvez esteja levantada ao final de nossa exposição de argumentos.

A intencionalidade desta argumentação é fomentar, no campo da pedagogia, um diálogo para a reflexão ao conceito de "formação", tendo em vista dois filósofos que preconizam a prevalência da vida sob todos os outros aspectos que poderiam se levantar na construção do conceito. Para isto, dividiu-se o argumento em quatro eixos: 1) o significado do termo "formação"; 2) a modernidade como defensora do conceito; 3) alguns dilemas da contemporaneidade e a noção formativa considerando rupturas e desconfianças em relação à possibilidade de se fazer uma formação; 4) o vigor de uma ideia - a educação como vida e para vida e o crescimento como uma noção formativa.

A premissa é tratar do conceito de crescimento deweyano e do cultivo de si nietzschiano, como propostas a reflexão sobre a formação no campo educativo. Tais, conceitos ora se aproximam ora se afastam provocando no diálogo um movimento capaz de dar ao leitor uma noção conflitante. A intenção é, exatamentente, esta: "incomodar" o intérprete para, então, provocar a abertura de outras possibilidades de constituição de

${ }^{1}$ A seis mãos, igualmente, se produziu a pesquisa de mestrado, defendida em 2014, na Linha de Pesquisa Filosofia da Educação, no PPGE/UFSC e intitulada Crescimento: John Dewey e sua contribuição à noção de formação no pensamento pedagógico moderno.

Filosofia e Educação [rfe] - volume 7, número 2 - Campinas, SP Junho-Setembro de 2015 - ISSN 1984-9605 - p. 143-169 
sentidos. Um modo de desalojá-lo de uma suposta verdade tal é nosso entendimento acerca do próprio ato do pensamento. Esta é também a tarefa da filosofia da educação, horizonte no qual nos movemos.

\section{Crescimento, cultivo de si e moral}

Crescimento é um conceito desenvolvido por Dewey em sua obra clássica de 1916, Democracia e Educação, e acompanha uma exposição filosóficoargumentativa linear. Diferentemente da ideia de cultivo de si, de Nietzsche, que acompanha uma forma de filosofia musicalizada, metafórica e aforística. Se ultrapassamos estas diferenças de formas podemos perscrutar nas suas filosofias algo que está colocado como contribuição ao campo da educação. Precisamos dar escuta aos argumentos no esforço hermenêutico de interpretação de suas filosofias para alcançarmos certa produtividade ao campo das teorias educacionais. Ambos, Dewey e Nietzsche, apesar do que há de específico em suas historicidades, nos dão a pensar a formação humana entranhada em uma perspectiva de filosofia prática e nada idealista. O termo "formação" é, para a pedagogia, um termo caro, precioso, consideravelmente valioso, visto sua aplicabilidade quando refere-se ao desenvolvimento cognitivo e escolar dos indivíduos. O formar pedagógico é atualmente a expressão de ordem para a construção de cidadãos críticos e ativos. $^{2}$

Deste modo, o objetivo é desenvolver um diálogo investigativo sobre o termo, levando em conta, uma noção mais ampla e menos engessada sobre o conceito. Neste caso, nos valemos da filosofia da educação deweyana como pedra de toque para uma análise do assunto. Já a filosofia de Nietzsche, nomeadamente na sua ideia de cultivo de si, nietzschiana

${ }^{2}$ Cabe dizer que não é nossa intenção neste momento discutir, detalhadamente, as posições diferenciadas destes dois pensadores sobre o conceito de democracia, algo que ficará em aberto neste ensaio.

Filosofia e Educação [rfe] - volume 7, número 2 - Campinas, SP Junho-Setembro de 2015 - ISSN 1984-9605 - p. 143-169 
adquiri um papel objetivo na formação, pois se trata de um conceito chave no crescimento, tal como analisamos aqui.

O que Dewey e também Nietzsche fazem é apontar na ação formativa uma fixação de práticas, anulando ou impedindo um desenvolvimento - cognitivo, psicológico, fisiológico e intelectual constante dos indivíduos.

Enquanto humanos, somos, em grande medida, capturados por projetos de formação que insistem em expandir-se. Historicamente, alguns itinerários formativos foram privilegiados e outros ainda estão a solicitar nossa atenção. O elemento do cultivo de si nos parece pertencer a esta gama de possibilidades formativas, ainda débil no conjunto da formação humana. Em grande parte, o tempero predominante da formação humana foi a moral. Nietzsche nos alerta, insistentemente para este ponto. Um determinado tipo de entendimento da moral que nos alcança até hoje. A moral sabe entusiasmar e por isto tanto nos seduz. No entorno da sedução acontece uma espécie de paralisia da vontade crítica, como se fosse desnecessária, tal o conforto de uma promessa por estabilidade da vida que a moral parece embalar.

O apelo da moral é convincente, pois agrega os justos, bons e virtuosos e assim ela imagina confortar, destacando um especial plano de ação: a moral diz como agir para ser feliz. Ela tornou-se, ao longo do processo civilizatório, um fundamento: age assim e sê feliz! Formar-se em Nietzsche implica examinar todo este suposto fundamento, fazer uma crítica de um tipo de razão que perdurou entre todos os tempos - o agir move-se por uma razão.

Em Dewey, a moral é exame, é a ação de duvidar sobre a maneira pela qual devemos agir quando a experiência não nos permite atuar com o

Filosofia e Educação [rfe] - volume 7, número 2 - Campinas, SP Junho-Setembro de 2015 - ISSN 1984-9605 - p. 143-169 
mesmo hábito que agíamos antes. A moral é uma deliberação consciente que não determina mais uma obediência e obrigação quase bélica.

O enfrentamento do problema da moral implica discutir o valor de uma determinada interpretação. Mas, em contrapartida, também implica pensar em outros valores possíveis para mover as ações. Para Nietzsche, moral é aquilo que intensifica a vida, promove sua expansão produzindo sentidos para viver. Esta definição é praticamente desconhecida por nós, uma vez que o termo moral está indicado por outros elementos. Em sua escavação, Nietzsche descobre uma inversão entre as categorias do Bem e do Mal. Para os gregos, no início, o Bem ficava evidente pela ação de um tipo de homem constituído de uma cultura singular, capaz de ações corajosas. O Mal era o homem destituído de uma formação e, por isto, frágil em sua atuação. Posteriormente, a lógica fica invertida: o modelo é do homem virtuoso, racional e eficaz à luz de uma Paidéia socrática e mais tarde, na época medieval, cristã (CAMBI, 1999). O mal fica estabelecido pelas ações singulares e fortes, não sensíveis à coletividade. A moral ganhou um novo componente: a coletividade, infelizmente desdobrado em um espírito gregário, uma moral de rebanho, como refere Nietzsche.

A moral, para Dewey, só se organiza no exercício do abandono da crença, como um caráter fixo, unitário e completo. O formar-se, em Dewey, tem um olhar atento à moral como processo dinâmico que evolui ao reconstruir as identidades humanas para expandir e diversificar os relacionamentos que constituem tais identidades que aumentará a capacidade de identificação das necessidades, interesses e perspectivas da diversidade humana. Este movimento, nada impositivo de algo bom em detrimento de um ruim, auxilia na renovação das vivências humanas e com isto atribui à educação uma noção formativa distinta da noção moderna pedagógica.

Filosofia e Educação [rfe] - volume 7, número 2 - Campinas, SP Junho-Setembro de 2015 - ISSN 1984-9605 - p. 143-169 
Nesta perspectiva, a formação exige um livrar-se das algemas para fazer outras experiências. As algemas metaforicamente representam muitas coisas, até mesmo os laços que estamos convencidos, pela moral, a manter. A retidão excessiva impede formação. E justamente quando nos deslocamos para outra direção, àqueles mais próximos sentem um estranhamento em relação às nossas condutas. Ficam aguardando nosso retorno ao caminho reto. A insistência com um caminho, com a retidão das condutas e das práticas simplifica e empobrece a vida humana.

No que se refere à ideia do cultivo de si, esta é, por excelência, uma ideia filosófica oriunda dos gregos, mas um problema de educação ainda vigente. Ideia convertida pelos estabelecimentos de ensino em erudição, em submissão a um idealismo moralista. Formação ressoou, ao longo do tempo, como eco de erudição e civilização. O cultivo de si implica cuidado consigo, defesa de si, um vir a ser que, no caso de Nietzsche, envolve um compromisso também com a filosofia, na sua radicalidade de envolvimento com a vida. Afirma:

O que hoje sou, onde hoje estou - em uma altura de onde já não falo com palavras, mas com raios -, ó quão longe disso eu ainda estava então! - Mas eu via a terra - não me enganei um instante sobre caminhos, mares e perigos - e sobre o êxito! A grande paz no prometer, o feliz mirar em um futuro que não permanecerá mera promessa! - Ali cada palavra vivida, profunda, interior; os sofrimentos maiores estão presentes, existem palavras cobertas de sangue. Mas um vento de grande liberdade sopra sobre tudo; a própria ferida não é sentida como obstáculo. (NIETZSCHE, 2008, p. 67). 
A ideia do cultivo de si dialoga com a ideia de crescimento em Dewey. O que afinal pode estar aí entrelaçado?

John Dewey é um filósofo, e um filósofo da educação, que vislumbra a noção do desenvolvimento humano para uma visão transmutável da moral. A sua noção educativa de formar para vida, em Democracia e Educação, nos oferece um novo olhar à noção de formação, pois crescer significa manobrar com desenvoltura o que nos é apresentado, inclusive o repertório moral. Implica fazer valer a plasticidade do espírito para ressignificar sentidos em face de novas demandas. Implica também, a plasticidade do espírito no enfrentamento com a dureza dos contextos e alterações de seus formatos. A ideia da formação que nos chega destes dois pensadores nos sugere que a vida solicita formação que tenha condições de atender suas variações.

\section{A modernidade como gênese da noção de formação}

A concepção formativa, a qual ainda somos herdeiros, pode ser definida como fruto da modernidade pedagógica. Este período da história foi em grande medida a idealizadora de um pensamento formativo a respeito dos seres humanos e sua educação. Está presente a concepção de que toda educação tem, em sua ação, o objetivo de constituir uma "forma" naqueles que por ela são tocados. A finalidade é movê-los em direção a uma cultura, costumes e tradições. A moral, conforme tratamos anteriormente, é a ancoragem para toda a ação, dada nestes termos formativos.

Mas a modernidade tem uma dialética e, por isso, é, também, considerada um momento de rupturas na história da humanidade. Ruptura em todos os sentidos: geográfico, político, ideológico, econômico, social, cultural e pedagógico. No campo geográfico, no que diz respeito ao deslocamento de um eixo histórico do oriente para o ocidente, com as

Filosofia e Educação [rfe] - volume 7, número 2 - Campinas, SP Junho-Setembro de 2015 - ISSN 1984-9605 - p. 143-169 
viagens, as colonizações, os contatos étnicos com a descoberta das Américas. No âmbito econômico, a troca do modelo feudal para o investimento no modelo capitalista. No social, o aparecimento de uma nova classe, a burguesia, que nasce junto com as cidades e o novo modelo econômico. Na visão religiosa, de um lado, a disseminação de uma multiplicidade de credos e de outro o "desencantamento do mundo", ao modo do diagnóstico weberiano. No ponto de vista ideológico cultural, as mudanças se efetivaram pela laicização e emancipação da mentalidade, pela valorização da razão.

Entre os saberes que serão legitimados pelo uso da razão, seguindo pelo pensamento analítico e experimental, encontramos o marco emblemático do iluminismo, que irá organizar este modelo mental e cultural através da oposição à metafísica e do seu estreito vínculo à ciência. Esta apareceu com a "liberação da humanidade" (TARNAS, 2003, p.305) apresentando-se como a salvadora da vida moderna. Em suma:

A visão de mundo moderno foi produto de uma extraordinária convergência de eventos, ideias e personalidades. Face à sua conflitante diversidade, gerou uma fascinante visão - de caráter radicalmente novo, com consequências acentuadamente paradoxais - tanto do Universo como do ser humano (TARNAS, 2003, p.245).

Todos estes aspectos, como já expôs Tarnas (2003), podem também ser considerados responsáveis pela revolução pedagógica e educativa. A formação, então, segue novos preceitos sociais. Orienta-se por novos valores e, com isso, estabelece novos modelos. Reavalia o inventário da tradição, passando a olhar "formação" como o contato do homem com a cultura e a vida social. Segue o modelo do homem capaz de transformar a 
realidade e dar a ela uma direção ideal. A modernidade cria o indivíduo como um ser ativo socialmente, humanizado, nutrido de uma fé laica e capaz de uma racionalidade efetiva e plena. Este é o seu projeto. Do mesmo modo, passa a considerar a sociedade como local formativo. A escola passa a ocupar o valor de instituição central para dar conta de uma função educacional, refinando suas capacidades orgânica e funcional. Com isso, mudam-se as teorias pedagógicas. Com a modernidade, é fortalecida a ideia da ciência da pedagogia, que tem como objetivo produzir a racionalidade.

Uma noção de formação para a criação de capacidades humanas renasce com a Modernidade. Uma nova visão para um novo momento histórico. Pode-se dizer que a modernidade influenciou na ideia formativa de um indivíduo socialmente ativo; uma formação para um fim social. As teorias filosóficas educativas modernas de Rousseau, Kant e Herbart, marcaram a concepção pedagógica da modernidade e mais tarde, entre os séculos XIX e XX, influenciaram positivamente John Dewey a estruturar sua teoria educacional e, agregada à ela, sua concepção sobre o crescimento.

\section{A leitura deweyana sobre a formação moderna}

John Dewey, como todo filósofo, não nega admiração por autores clássicos. Em Democracia e Educação, no capítulo seis, reporta-se a Herbart, para estabelecer parâmetros entre "A educação conservadora e a educação progressista", tratando a educação como ferramenta da formação.

Segundo Dewey, Herbart vislumbra a educação "como instrução [sendo] a edificação feita, de fora para dentro, no espírito". (DEWEY, 1959, p. 75). Do mesmo modo ele refere-se a Rousseau, no capítulo sete "A concepção democrática da educação", ao tratar do ideal individualista do século XVIII. A educação caracteriza-se, de acordo com a natureza, como um "método de instruir e disciplinar" (DEWEY, 1959, p.98). Da mesma

Filosofia e Educação [rfe] - volume 7, número 2 - Campinas, SP Junho-Setembro de 2015 - ISSN 1984-9605 - p. 143-169 
maneira refere-se a Kant, no capítulo vinte e seis, "Teorias da Moral", quando descreve que a moral verdadeiramente importante não é somente o que o homem tem na consciência, mas principalmente nas suas ações, ou seja, "aquilo que ele faz” (DEWEY, 1959, p. 383).

John Dewey vê nesses filósofos contribuições importantes para o campo da educação. Dewey tem ressalvas em relação aos filósofos, contudo prioriza neles aquilo é positivo para o debate sobre formação. Defende que a capacidade formativa do homem, que tem como objetivo o crescimento contínuo, estabelece uma efetiva relação entre educação e vida. $\mathrm{O}$ conceito de crescimento satisfaz os requisitos de uma noção de formação, porque institui um compromisso intelectual de conduta. Mas não haveria um esvaziamento de sentido nesta formação, se for pensada a partir do par crescimento-cultivo de si, tal como interpretamos aqui.

Nietzsche, o filósofo do martelo, também analisa a modernidade e realiza uma crítica mais feroz, a marteladas mesmo. Indica uma filosofia para o futuro pautada pela coragem de um pensamento capaz de resistir ao seu tempo e à sua história quando se faz necessário. As ideias modernas são mais senis que as antigas e o filósofo se vê como um mensageiro de uma nova cultura, de um outro destino, uma nova aurora. Posições presunçosas, mas imbuídas de uma convicção que não suporta desperdiçar o ar livre, o caminho para cima fruto de um pensamento indomável. Não suporta a pressa. Não suporta incapacidade humana de tomar o tempo para ruminar. Para esperar. Para esquecer. Para criar.

Ao final da obra Ecce homo, Nietzsche delineia uma ambição filosófica: não deseja dirigir-se às massas, dá as costas aos crentes, e jamais imagina ser classificado como santo. Nesses termos, empenha-se em ganhar antipatias, em produzir impactos, gerar aversões para jamais ser confundido com um idealista. É um filósofo que, por vezes, nos entristece, talvez mais,

Filosofia e Educação [rfe] - volume 7, número 2 - Campinas, SP Junho-Setembro de 2015 - ISSN 1984-9605 - p. 143-169 
nos aborrece com o que diz. Temos a tendência de evitar revelar o que nos incomoda, mas ler Nietzsche implica também digerir o que não compreendemos, o que não gostamos, o que rejeitamos. Um autor não é para ser consumido e convertido em peça publicitária, adereço de nós mesmos, um pensador tem como tarefa nos fazer tombar, em certa medida viver a transvaloração dos valores e suportar o que a experiência vai nos exigir.

Por isso estamos, inclusive, provocando um diálogo entre Dewey e Nietzsche, sem a pretensão e produzir acordos e consenso. Colocá-los lado a lado para pensar. Investigar como cada um deles entende a modernidade e qual a tarefa dos humanos nesse entorno. As críticas são diversas, mas ambos valorizam a força do indivíduo para inaugurar interações mais efetivas entre educação e vida.

Nietzsche é ácido em relação à verdade revestida de moral e inventada pelos homens para castrar os instintos da humanidade. Afinal,

tudo o que se chamava "verdade" é reconhecido como a mais nociva, pérfida e subterrânea forma de mentira; o sagrado pretexto de "melhorar" a humanidade como ardil para sugar a própria vida, torná-la anêmica. Moral como vampirismo... Quem descobre a moral descobriu com isso o não-valor dos valores todos nos quais se acredita ou se acreditou; nada mais vê de veneração nos tipos mais venerados e inclusive proclamados santos, neles vê a mais fatal espécie de aborto, fatais porque fascinavam... (NIETZSCHE, 2008, p. 108).

Em consonância, Dewey, em sua filosofia educacional declara que 
as ideias morais correntes cindirem o curso da atividade em dois fatores contrários com frequência chamados respectivamente de o interior e o exterior, ou o espiritual e o material. Esta divisão é uma culminação do dualismo do espírito e do mundo, da alma e do corpo, do fim e dos meios, que tantas vezes já notamos (DEWEY, 1959, p. 380).

Dewey é o primeiro filósofo naturalista a desenvolver uma teoria da formação tendo como base o crescimento. Neste, a conduta humana não é desenvolvida unicamente pela moral, vampiresca, binária, mas pela criação de hábitos capazes de transformá-la. Pois

[...] O fato é que a moral tem a mesma largura que nossas relações com os outros homens. E potencialmente isto inclui todos os nossos atos, [..]. Pois cada ato, pelo princípio do hábito, modifica nossa mente - fixa certas espécies de disposições e desejos.

[...] A moral se interessa nada menos que por toda a atitude, e essa atitude total se identifica com o homem em toda o seu aspecto e manifestações concretas (DEWEY, 1959, p. 392;393).

Por isso, seu valor formativo tem em si o próprio valor, não possui fim. Concluir, modelar, moralizar o homem seguindo um ideal definitivo, interno ou externo: é isso que se tenta, até hoje, a todo tempo na ação educativa. Quando iniciamos um jovem no processo de ensinoaprendizagem, modela-se a sua conduta, tendo como referência um ideal externo ao seu desenvolvimento. Diferentemente a isso, o fim educativo de John Dewey objetiva um desenvolvimento da conduta por um processo contínuo de educação. O jovem não precisa de um fator externo que o forme, tudo que ele precisa para desenvolver-se está nele desde seu 
nascimento. Mas ele também precisa ser tocado pela vida. Deixar-se tocar, não enregelar-se nas duras e frias paredes do mesmo que a educação, por vezes, insiste em manter. A educação, neste sentido, tem como função coordenar e auxiliar a busca de um método capaz de tornar o desenvolvimento de suas capacidades um fator interminável, demonstrando que o resultado educativo é a constante busca por mais crescimento. E terá como resposta um movimento constante de modificação interna e externa deste sujeito, isto inclui seu valor moral e social.

\section{A contemporaneidade e a dimensão da formação}

O século XIX foi o século da mudança mundial mais profunda em relação à ciência e à técnica, e dentro desta mudança altera-se a concepção de homem. A cientificização do século XIX mostra que o homem não está mais ligado a uma constituição divina, mas sim a uma ideia de natureza humana, que possui uma consciência psíquica e tem ação direta em suas ações.

Tais mudanças alteraram a concepção educacional deste tempo. O pensamento pedagógico entre os séculos XIX e XX baseia-se na fundação da pedagogia científica e experimental. Dewey foi, neste período, o filósofo que se preocupou com a educação, tendo como marco a sua obra Democracia e Educação. Esta prioriza uma concepção educativa pautada não mais em uma formação fixa do homem para uma ação e função social, mas sim em uma educação que possui como resultado a continuidade do crescimento, uma intencionalidade para o constante crescer ou cultivar-se. Idealiza-se um homem múltiplo, ou seja, um indivíduo que não atua em apenas uma faceta social e sim em muitas associações da mesma e, nelas, tem habilidades e capacidades específicas a serem desenvolvidas constantemente. 
Dewey mostra uma forte contribuição para um novo entendimento de formação para a pedagogia do século XX. Um filósofo orgânico, que traz consigo um novo modelo pedagógico, influenciado pelas ciências naturais e pela concepção pragmática. A teoria filosófica deweyana é focada em uma noção de experiência, que desenvolve uma interação entre sujeito e natureza ativa, sendo capaz de transformar ambos, mas não lhes impondo fim; ao contrário, propondo-lhes uma preceptiva constante.

Assim, o homem deweyano é caracterizado pela construção de um método de pensamento na criação de uma inteligência ativa e criativa. Tem domínio da sua experiência quando se utiliza de um uso lógico do pensamento. Isso não significa uma propriedade de algo chamado intelecto ou razão, separado da natureza, mas de "um modo de ação externa dirigida" (AMARAL, 1990, p. 62), entendido como método do pensamento reflexivo. E neste método os sentidos, a imaginação e a arte são também considerados para o crescimento, sendo ferramentas da experiência que irão operar um desenvolvimento inteligente, orgânico e criativo. Neste modelo filosófico educativo, Dewey desenvolve sua noção democrática, que é a mais avançada associação entre os indivíduos, sendo constantemente reconstruída por meio da educação. Por estes motivos, John Dewey desenvolve um argumento interpretando o termo "formar" de maneira distinta da visão pedagógica moderna. O "formar", para a teoria educacional deweyana, ocorre por meio de um contínuo exercício.

E assim o projeto educativo deweyano sofre ásperas críticas que vão desde o esvaziamento dos valores formativos que sua teoria, supostamente, apresentaria até o problema de uma à valorização excessiva das atividades experimentais. Ademais, compreenderam o experimento como mera senha para a progressiva democratização da sociedade.

Filosofia e Educação [rfe] - volume 7, número 2 - Campinas, SP Junho-Setembro de 2015 - ISSN 1984-9605 - p. 143-169 
Os críticos da filosofia da educação de Dewey deixaram de observar alguns detalhes importantes nela. No que se refere a sua relação com o pragmatismo, Dewey vai para além da noção de teoria e prática, ultrapassa o fazer pedagógico como centralidade na ação educativa. A influência pragmática está na origem da ideia de aquisição do conhecimento, na articulação do método educativo pautado na investigação, no interesse, como ainda na disciplina mental por meio da aplicação de um método educativo do pensamento.

Percebemos que há na filosofia da educação de John Dewey uma articulação contínua entre experiências, o que pode ser profícuo ao campo da educação. No entanto, sua proposta de aproximação com a pesquisa das ciências experimentais para a aquisição de soluções aos problemas pedagógicos pede cautela. A complexidade do suposto objeto, de um e outro campo, implica tratamentos diferenciados. Talvez pudéssemos tematizar que, a despeito da influência das ciências naturais em sua abordagem do crescimento, o que o filósofo parece querer é destacar o elemento orgânico, como sinônimo de vida, mais do que reduzir o crescimento humano ao paradigma das ciências naturais. ${ }^{3}$

Nietzsche provoca em nós uma outra relação com a vida, diferentemente de Dewey, nos apresentando a uma dimensão trágica da vida, que sempre chega a nós inteira, sem possibilidade de eliminar o que nos desagrada. A vida chega com intensidade, e nos surpreende em função de tudo que pode inaugurar em nós. Além disso, com Nietzsche está em curso, desde sempre, um elemento de indeterminação do humano que não pode ser circunscrito à base biológica.

${ }^{3}$ Este ponto está em fase de estudos e pesquisa e será objeto de análise em outro momento.

Filosofia e Educação [rfe] - volume 7, número 2 - Campinas, SP Junho-Setembro de 2015 - ISSN 1984-9605 - p. 143-169 


\section{A Educação como vida e para vida}

A concepção de vida, para Dewey, tem as nuanças da teoria naturalista a qual ele defendia. O filósofo considera a vida um "conjunto de experiência, individuais e raciais. [...] A palavra vida refere-se aos costumes, instituições, crenças, vitórias e derrotas, divertimentos e ocupações" (DEWEY, 1916, p.4). É o movimento orgânico do indivíduo com o meio. A "vida" é empregada neste conjunto diverso de sentido, assim como a palavra "experiência" também é empregada com esta conotação, pois ambas estão associadas. Desta maneira, "vida" e "experiência" são sinônimos, pois quando se atribui o termo "vida" para designar a existência de um indivíduo de maneira física, também se emprega o termo "para indicar toda a extensão da experiência do indivíduo e da espécie.” (DEWEY, 1959, p.2). O termo "vida", para Dewey, tem um caráter fisiológico, como de costume nas ciências naturais, e um caráter social (tanto no sentido individual quanto no coletivo). É perante esse segundo plano que o autor irá tratar o que consideramos sua filosofia da educação. Assim, ele define a educação como o processo de reconstrução e reorganização da experiência capaz de direcionar melhor os cursos de futuras experiências. Portanto, a educação se torna mais evidente como um fenômeno direto da vida.

John Dewey "cria uma filosofia que reconhece a origem, o lugar e a função da mente na natureza" (AMARAL, 1990, p.25). Abandona a ideia dicotômica entre "conhecimento e crenças, pensamento e ação, método e matéria, fatos e valores, ciência e filosofia" (AMARAL, 1990. P 25). Constitui um homem livre, que conhece cada vez mais, porque reconhece o mundo em que vive devido a sua inteligência, a qual é o objetivo do crescimento.

Portanto, ao desenvolver a noção de crescimento, Dewey também desenvolve uma noção que satisfaz uma concepção formativa. Possibilita,

Filosofia e Educação [rfe] - volume 7, número 2 - Campinas, SP Junho-Setembro de 2015 - ISSN 1984-9605 - p. 143-169 
assim, uma análise das demais teorias da educação, vislumbrando um ideal educativo que não seja estático e que aconteça durante toda a existência do indivíduo. Oferece, ainda, ferramentas para agir perante o meio social, com o objetivo de desenvolver uma aprendizagem mais significativa e autônoma. Determina, portanto, o crescimento como um valor social. Então, os critérios deweyanos de formação são: o processo educativo como uma aprendizagem para toda a vida; o desenvolvimento no indivíduo em um método autônomo para a aprendizagem (aprender a aprender); e a aprendizagem agora como sinonímia de crescimento, denotando um valor social.

A aprendizagem para toda vida nada mais é que o fenômeno direto de reconstrução da vida. Esta se caracteriza pela força ora de constância ora de resistência, que se renova, mesmo ao parecer que está destruída. Envolve conflito do organismo com o meio. Para Dewey, nem a morte interrompe a vida; quando um indivíduo se vai, a vida de outros continua, mantendo sua complexidade. Os seres vivos são capazes de se readaptarem, fazendo com que se perpetuem. A vida social em nada se diferencia da vida animal. Ambas possuem os mesmos mecanismos de preservação e adaptação ao meio. A vida social se perpetua tendo como ferramenta a educação, e é por meio dela que se constitui a transmissão, através da comunicação, e a renovação social, através do crescimento.

Pode-se identificar, em Dewey, que os fins da vida se relacionam com o processo de viver. Por isso, os resultados da educação são relacionados com os processos e funções da vida. A educação é permanente. Seu resultado se transforma em processo, e no processo reside novo resultado, definindo bem a concepção da aprendizagem. Assim, o crescimento é expansivo como os ramos de uma árvore na diversificação da linguagem, das espécies. A evolução é a árvore da linguagem das 
experiências individuais compartilhadas. O tronco é a experiência primeira; e os galhos e ramos são as variações ocorridas durante o processo do viver, por meio da comunicação e da reorganização e reordenação individual. Do mesmo modo que a árvore não deixa de abrir ramos, o crescimento também não para, só expande-se em mais crescimento.

A educação deweyana não é entendida como "preparação, que se localiza entre este ou aquele período de vida" (WESTBROOK; TEIXEIRA, 2010, p. 39). Mas, devido à condição de imaturidade presente em menor ou maior grau - não importa se seja criança, jovem, adulto ou idoso -, todos são capazes de participar do caráter educativo disponibilizado pela experiência. Neste sentindo, o que se pode ter são graus de educabilidade devido aos critérios do crescimento, dependência e plasticidade, que dão a potencialidade imatura do indivíduo. Como exemplo: a criança poderá aprender com mais rapidez e destreza devido ao baixo nível de experiências acumuladas, consequentemente terá maior imaturidade segundo seus critérios observáveis de dependência e de plasticidade. Por outro lado, o idoso terá maior número de experiências vividas e comunicadas, terá assim menor imaturidade, devido a seu nível menor de plasticidade, tornando-se mais restrito à aprendizagem. Porém, em ambos, o objetivo é que educação se subordine à própria educação, para que haja um prolongamento da imaturidade. É desejável exercitar uma imaturidade potencial e ativa. Dewey já havia se referido a isso, em Como Pensamos (1910), quando afirmou que o pensamento reflexivo propõe atitudes de "prolongamento da dúvida" (que por sinal tem sua raiz nos artigos de Pierce). É no capítulo quatro de Democracia e Educação que John Dewey menciona o adulto ensaiando a atitude aprendente e curiosa da criança.

Portanto, a educação tem como conceitos equivalentes a vida e a experiência. Assim, o objetivo da educação é habilitar o indivíduo a mais

Filosofia e Educação [rfe] - volume 7, número 2 - Campinas, SP Junho-Setembro de 2015 - ISSN 1984-9605 - p. 143-169 
educação, continuamente. Então, ocorre o crescimento contínuo de hábitos inteligentes capazes de promover a mudança como um ideal social. Isso para promover a constante ideia de vida e seu sinônimo, a educação.

A noção de aprender a aprender denota autonomia. De acordo com Dewey, a necessidade do homem de aprender se dá para utilizar seu grande número de tendências instintivas. Em alguns casos, o corpo aprende por si, como é o caso dos instintos dos sentidos. Mesmo eles precisam ser ensinados, para que não desenvolvam apenas tarefas mecânicas. Os sentidos têm de ser ensinados a fazer diversas combinações para que o indivíduo possa utilizar deles com destreza e aperfeiçoamento. Isso ocorre diferentemente dos animais, que horas depois de nascer são capazes de coordenar seus sentidos. Isto se dá porque o animal possui um aparelho inato relativamente programado, "Ao passo que a criança tem a vantagem da multidão de reações instintivas feitas em tentativas sem fim e da experiência obtida com isto" (DEWEY, 1959, p.48). A prática de aprender não é algo que se nasce sabendo fazer. Aprende-se, e se permite que o indivíduo seja capaz de aprender, a variar as maneiras de usar a mesma experiência. Obriga-o a fazer combinações de acordo com as circunstâncias a que é submetido. Em suma, "aprendemos um ato e desenvolvemos métodos bons para outras situações" (DEWEY, 1959, p.48). Esse fator possibilita o contínuo progresso das habilidades latentes dos sujeitos.

Aprender nada mais é do que um hábito inteligente, o qual significa instruir-se a fazer combinações variadas, isto é, "Aprender a Aprender". Tal expressão é utilizada pela pedagogia contemporânea como uma capacidade puramente prática, não identificando suas sutilezas quando cunhada por Dewey, no quarto capítulo de seu livro, em 1916.

Desse modo, quanto mais aprendemos a aprender, ou seja, quanto mais variadas combinações fizermos com os hábitos, os quais adquirimos

Filosofia e Educação [rfe] - volume 7, número 2 - Campinas, SP Junho-Setembro de 2015 - ISSN 1984-9605 - p. 143-169 
durante o processo educativo, mais continuidade terão a experiência, o crescimento, o aprendizado e os novos hábitos. Estes só serão subordinados a eles mesmos, ou seja, experiência gera experiência, crescimento gera crescimento, hábitos geram hábitos. Eles estão ligados ao critério do “aprender a aprender”, por isso a educação é, para Dewey, responsável por assegurar esta continuidade, através da orientação das capacidades da noção permanente do desenvolvimento.

Aprender é, também, sinônimo de autonomia. Aprende-se por meio de um método de desenvolvimento do pensamento inteligente, ou hábitos inteligentes. A aprendizagem se torna consciente e, com isso, o indivíduo compreende que basta a experiência ser significativa para produzir uma inquietação. A partir da formulação consciente da inquietação, adquirirá interesses e objetivos. O indivíduo está pronto para, sozinho, desenvolver formas que solucionarão problemas em sua vida. E quanto mais variadas as maneiras de solucionar, maior será o seu desenvolvimento posterior, fazendo dele um ser autônomo para aplicar seu aprendizado durante a vida e para modificar constantemente as circunstâncias.

A aprendizagem agora como sinonímia de crescimento, denotando um valor social. Aprender é o grande valor do crescimento. Valor que está ligado à capacidade do aumento da ação democrática. Aprender significa ser capaz de atuar no mundo com mais confiança e colaboração, considerando que a experiência ancora-se no mundo. É desenvolver a capacidade de comunicar-se e de ampliar a experiência, com o objetivo ininterrupto do crescimento.

O crescimento, em sua primeira instância, o fim, do qual a democracia é o meio. Ele é base para uma sociedade que se constitui de várias associações humanas que se ligam com interesses compartilhados. Elas têm, em seus membros, os responsáveis por desenvolver experiências e

Filosofia e Educação [rfe] - volume 7, número 2 - Campinas, SP Junho-Setembro de 2015 - ISSN 1984-9605 - p. 143-169 
comunicá-las, de maneira contínua, entre eles e as demais associações. Promovem, dessa forma, a aprendizagem variada e o progresso contínuo.

A educação, segundo John Dewey, assume um papel importante no campo social e, consequentemente, político. A dimensão política é consequência do ato educativo, não uma mera preocupação do filósofo trata-se da formação da ação do indivíduo, a qual se denomina democracia. Portanto, a democracia é uma maneira de se viver em sociedade que favorece o acontecimento das experiências e que, por seu turno, implica crescimento. Um modelo social que tem como intensão a constante mudança, resultando no desenvolvimento infindável do sujeito. A ele oportuniza-se um crescimento com bases em uma mentalidade científica e colaborativa, o qual tem como meta mais crescimento.

A democracia, em Dewey, é o desejo de aprender a aprender. Tem como objetivo o contínuo crescimento e, com isso, a constituição da mudança que marca o conceito de democracia. "O critério do valor da educação está na extensão em que ela suscita o desejo de desenvolvimento contínuo e proporciona meios para esses desejos" (DEWEY, 1959, p.57).

Pode-se afirmar que a filosofia da educação de John Dewey tem no crescimento uma noção que satisfaz a noção de formação. Não uma noção que equivale a um fim para um determinado objetivo, mas um fim que se torna objetivo, pois a continuidade do desenvolvimento é a verdadeira ideia de formação na teoria pedagógica deweyana.

Nesse ponto é quase impossível aproximar os dois autores aqui referidos. Será preciso tomá-los como referências para pensar. Cada um a seu modo. Nietzsche recusa a democracia, ainda que não a política. Tem outros entendimentos sobre como viver em sociedade. Apesar disso, também privilegia a vida, o cultivo de si, o devir que em alguma medida implica em vida, em atividade sempre.

Filosofia e Educação [rfe] - volume 7, número 2 - Campinas, SP Junho-Setembro de 2015 - ISSN 1984-9605 - p. 143-169 
Para Nietzsche a afirmação do cultivo de si ancora-se na ideia do pathos e não da ação. Não se determina racionalmente uma vivência, mas avalia-se o vivido e sua capacidade de produzir o pathos de excesso. Nietzsche utiliza ainda a metáfora do jardineiro ao afirmar que, quanto mais vivências, mais somos capazes de garantir um solo para outro bem como evitar o nascimento de espécies indesejáveis. Tornar-se o que se é implica reconhecer esta aventura do cultivo de si que apresenta também uma dimensão ética e estética. O acesso racional a vida é impossível, cabe assumir sua dimensão estética, trágica, para enfrentar a vida em seu excesso, em sua abundância. Suportar a tensão entre sensibilidade e razão. A dor, a crise, a rejeição, a doença não são planejadas, mas devem ser enfrentadas uma vez que a vida se apresenta também com esta face. E nesse excesso de vida, aparece um ser humano ético, capaz de compreender como a vida pode se apresentar para tantos outros. O resultado não é a compaixão, nem a democracia, mas o reconhecimento de um homem mais elevado. O "elevado" nada tem a ver com privilégio, mas força, coragem, afirmação da vida.

O que se vive pode ser avaliado, a genealogia, capaz de fazer o ser humano mastigar, escavar as vivências para selecionar àquelas que deseja cultivar em seu "jardim". O processo formativo é tortuoso, exige rigor, necessita de ar, luz, água, parte de uma vontade tão singular que é capaz de reconhecer e respeitar outros tantos jardins, dissonantes do seu.

Ter espírito livre significa ser fiel a si mesmo, suportar a concisão de nossas condutas, já que a vida sem qualquer antecipação nos alcança em vivências que nos obrigam a pensar novamente. Brevidade, sim, talvez seja mais importante ser breve para fazer acontecer um processo formativo em constante devir, incapaz de deixar solidificar convicções que, transformadas

Filosofia e Educação [rfe] - volume 7, número 2 - Campinas, SP Junho-Setembro de 2015 - ISSN 1984-9605 - p. 143-169 
em crenças, impedem o cultivo. Acaba fazendo murchar a semente antes mesmo de ser cultivada.

Enfim, o cultivo de si em cada um desses autores tem nuances próprias e o fato de algo "murchar" em termos formativos impacta diferentemente em cada um deles. Por isso somos convidados a pensar outra vez sobre formação e sempre outra vez. Não para amarrar, sintetizar, sacralizar o certo, contudo deixar-se provocar infinitamente pelo que apresenta-se como estranho e desperta nossa curiosidade outra vez.

\section{Conclusão}

O movimento de mudança é declarado tanto em Dewey quanto em Nietzsche. Fica evidente também a maneira de fazer filosofia, ou seja, a linguagem explicativa utilizada para tratar dos autores demonstra mais uma de suas diferenças de abordagem filosóficas. Mas, o propósito destas seis mãos, destes trinta dedos e destas múltiplas cabeças e eus filosofantes é demonstrar, aos olhos de quem lê, os diversos tons dos autores e como estas nuanças podem ser tornar próximas e harmônicas em certas notas para que seja possível tocar e despertar o interesse daqueles que nos contemplam para uma reflexão ao tema da formação.

Este artigo teve como intuito apresentar aspectos da teoria do crescimento deweyano e declarar que Nietzsche, assim como outros, antes do filósofo estadunidense, já era movido a repensar a condição da formação do homem e constituí-lo longe dos dualismos da tradição.

Assim, queremos apenas salientar que a educação deweyana tem no conceito de crescimento o resultado da ação pedagógica e da ação educativa que se perpetua por toda a vida. É a capacidade humana, interna e externa, para aprimorar seu conteúdo inato e social. É pelo crescimento que o homem transforma o meio em que vive, para sobreviver. Por meio dele que

Filosofia e Educação [rfe] - volume 7, número 2 - Campinas, SP Junho-Setembro de 2015 - ISSN 1984-9605 - p. 143-169 
o indivíduo se adapta a conviver em associação humana. Produz nele e nela a capacidade de mudar constantemente. Essa disposição para a ação contínua da mudança é a democracia, a qual torna-se o resultado constante do crescimento, que na filosofia da educação de John Dewey satisfaz uma noção de formação, pois possui em si um valor intrínseco à sua concepção e um compromisso com a conduta humana. A mudança, responsável pela ação democrática, segundo Dewey, estabelece uma nova concepção educativa quando não reforça a ideia de um ideal, e sim atribui um valor ativo e mutável à educação.

Assim, a formação para Dewey não é fixa, modelada de fora para dentro. Não é carimbo de capacidades e habilidades através da imposição moral externa. A formação pelo crescimento deweyano é maleável, transmutável, reordenável. É o exercício das capacidades latentes do ser humano, o qual é reorganizado segundo sua capacidade inata do hábito de pensar, bem como aprimorado por meio de um contínuo método de reflexão sobre a experiência. Em suma, John Dewey não vê o homem como um produto do meio, e sim o homem e o meio como produtos do homem, além de perceber uma relação cooperativa entre ambos.

Para Nietzsche, a solidez, a insistência com imagens e conceitos fixos, a crença na virtude inviolável, são atitudes impróprias para um educador. Um educador-jardineiro que, a rigor, sempre tem uma ideia de estética, precisa estar habilitado para criar outras paisagens, renunciar aos hábitos vigentes, dar à beleza outra dimensão. $\mathrm{O}$ ato criativo tende a ser incompreendido, o que em parte justifica a originalidade do criador. Em alguma medida os educadores avançam quando aprendem a conviver com a solidão, aquela capaz de fazer ruminar uma ideia para acreditar que vale a pena defendê-la, mesmo sem aliados.

Filosofia e Educação [rfe] - volume 7, número 2 - Campinas, SP Junho-Setembro de 2015 - ISSN 1984-9605 - p. 143-169 
Para Nietzsche, a distância, a solidão, produziu sua crítica feroz à modernidade para analisar e avaliar a décadence de sua época. Mas a solidão não impediu a afirmação da sua filosofia, para diferenciar-se do seu tempo, apresentar sua ambição filosófica.

Como educadores precisamos também de distância dos solos educativos para escavar suas camadas, descobrir experiências encobertas, capturar novas sementes, para assim reafirmar e reconhecer a vontade própria tão silenciada pela vontade da maioria. Ao mesmo tempo a distância deve permitir ouvir os deslocamentos de alguns outros também movidos pela curiosidade de reencontrar-se para tornar-se o que se é.

Dewey, mesmo não utilizando o termo "formação" para designar um resultado da educação, acaba utilizando o crescimento como possibilidade, com uma perspectiva infinita. Desenvolve uma teoria que possibilita observar as demais teorias da formação com um olhar mais crítico ao termo. Apresenta três critérios de análise: a formação deve entender que a educação possui aprendizagem para toda a vida; a aprendizagem precisa desenvolver o processo de autonomia por meio do 'aprender a aprender'; e o aprender é o grande valor do crescimento.

A teoria do crescimento aqui defendida contribui para a pedagogia com uma visão formativa diferente daquela que idealiza um homem. Dewey não possui um ideal de homem, mas possui um valor intrínseco a ele, que favorece a constituição de uma ação humana, que determina uma constante mudança. Tem como base a criação de hábitos mais inteligentes. Prioriza o uso do pensamento como ferramenta de aprendizagem mediante a experiência. Toma, a contrapelo da moral vigente, a imaturidade humana como potência ao aprendizado. Gera um valor que resulta em mais aprender. Uma educação para toda a vida, e este valor é o que denomina "crescimento".

Filosofia e Educação [rfe] - volume 7, número 2 - Campinas, SP Junho-Setembro de 2015 - ISSN 1984-9605 - p. 143-169 
A empreitada de Nietzsche vai em outra direção. As travessias de um homem afirmam uma filosofia que tardiamente ganha notoriedade. Sua pretensão foi afirmar a vida e fazer explodir o desejo de viver em abundância por todos os lados da terra e do corpo. Contudo afirmar a vida em Nietzsche significa recusar "invenções modernas" para arriscar-se em outras direções.

Educadores em crescimento estão implicados por muitas perspectivas e nesse artigo oferecemos duas. Cabe ao leitor deixar-se provocar por elas, adentrá-las mais, investigar e selecionar roteiros de travessia de acordo com aquilo que agora cada leitor recusa e afirma.

\section{Referências}

ALI, Thaís. Crescimento: John Dewey e sua contribuição à noção de formação no pensamento pedagógico moderno. Florianópolis: UFSC, 2014. Dissertação (Mestrado). Universidade Federal de Santa Catarina. Programa de Pósgraduação em Educação.101p.

AMARAL, Nazaré de C. Pacheco. Dewey: Filosofia e Experiência Democrática. São Paulo: EdUSP; Perspectiva, 1990.

CAMBI, Franco. História da Pedagogia. São Paulo: Editora da UNESP (FEU), 1999.

DEWEY, John. Democray and Education. The Middle Works, 1899-1924. V.9. Sid Hook. 2008.

Democracia e Educação. Trad. Godofredo Rangel e Anísio Teixeira. São Paulo: Companhia Editora Nacional, 1959.

HOZ, Victor Garcia (org.) Dicionário de pedagogia labor. 2.ed. Barcelona, Espanha: Labor, 1970.

NIETZSCHE, Friedrich. Ecce bomo: como alguém se torna o que é. São Paulo: Companhia das Letras, 2008.

Filosofia e Educação [rfe] - volume 7, número 2 - Campinas, SP Junho-Setembro de 2015 - ISSN 1984-9605 - p. 143-169 
- O crepúsculo dos ídolos, on como se filosofa com o martelo. Trad. Paulo César de Souza. São Paulo: Companhia das Letras, 2006.

_. A genealogia da moral. Petrópolis, RJ: Vozes, 2009.

_. Gaia ciência. Trad. Paulo César Souza. São Paulo: Companhia das Letras, 2001.

- Humano, demasiado bumano. Trad. Paulo César Souza. São Paulo: Brasiliense, 2000.

Aurora. Trad. Mário D. Ferreira Santos. Petrópolis, RJ: Vozes, 2008.

SEVERINO, Antônio Joaquim. A busca do sentido da formação humana: tarefa da Filosofia da Educação. São Paulo. Educação e Pesquisa. n. 3. Vol. 3. 2006.

TARNAS, Richard. A epopeia do pensamento ocidental: para compreender as ideias que moldar nossa visão de mundo. 6.ed. Trad. Beatriz Sidou. Rio de Janeiro: Bertrand Brasil. 2003.

VIESENTEINER, Jorge Luiz. Aprender a ver, aprender a pensar, aprender a falar e escrever: condições do conceito de bildung no crepúsculo dos ídolos de Nietzsche. Artigo no prelo e disponibilizado em palestra proferida na UFSC em 2011.

WESTBROOK, Robert B; TEIXEIRA, Anísio. John Dewey. Recife: Massangana, 2010. (Coleção Educadores). 